\title{
Quantum chemical study of reaction mechanism of $[4+2]$-cycloaddition between 2,3-dimethylbuta-1,3-diene and methyl acrylate
}

\author{
Yaroslav Kovalskyi ${ }^{a}$, Olga Marshalok ${ }^{b}$, Natalia Vytrykush ${ }^{a}$ and Halyna Marshalok ( $^{{ }^{*}}$
}

${ }^{a}$ Lviv Polytechnic National University. 12 Stepan Bandera Str., Lviv 79013, Ukraine

${ }^{b}$ Danylo Halytsky Lviv National Medical University, 69 Pekarska Str., Lviv 79010, Ukraine

c'Jan and Jedrzej Sniadecki University of Technology and Life Sciences in Bydgoszcz, 85-225, Bydgoszcz, Poland

\begin{tabular}{l} 
C H R O N I C L E \\
\hline Article history: \\
Received August 21, 2016 \\
Received in revised form \\
October 24, 2016 \\
Accepted 10 November 2016 \\
Available online \\
10 November 2016 \\
\hline Keywords: \\
Mechanism \\
[4+2]-cycloaddition, 2,3- \\
Dimethylbuta-1,3-diene \\
Methyl acrylate
\end{tabular}

\begin{abstract}
A B S T R A C T
The quantum-chemical modeling mechanism of the [4+2]-cycloaddition reaction of 2,3 dimethylbuta-1,3-diene and methyl acrylate was conducted. Its qualitative aspects were analyzed at the molecular level by the program MOPAC2012 and semiempirical method RM1. The potential energy surfaces of 2,3 dimethylbuta-1,3-diene and methyl acrylate [4+2] cycloaddition possible reaction pathways were constructed by restricted and unrestricted Hartree-Fock approximation. It has been established that the molecule of the final product methyl-3,4-dimethylcyclohex-3-encarboxylate has the half-chair shape, wherein the carboalkoxyl group is in the exo-orientation. Interaction between molecules of 2,3 dimethylbuta-1,3-diene and methyl acrylate occurs by a two-step mechanism more likely than one-step, since the activation parameters of this interaction maximum coincide with the experimental data.
\end{abstract}

\section{Introduction}

Mechanism of Diels-Alder reaction has been the subject of much interest and disputes since it was found. ${ }^{1-3}$ Sometimes chemical evidences are not enough to set reaction path. The problems concerning the timing of forming and breaking bonds are principally difficult to solve by experiment. Theoretical calculations can be important in situations of this kind, and a number of calculations for Diels-Alder reactions have been reported..$^{2-8}$ Computer technologies advances in quantum chemistry provide an opportunity to explore the theoretical aspects of some chemical reactions. ${ }^{6-8}$ And use of these kind technologies provides a significant aid in the experimental studies to elucidate the mechanism of DielsAlder reaction. Furthermore, the theoretical description of forming and breaking chemical bonds in molecules during their interaction, associated with changes in the electronic structure of the reactants, requires the use of quantum-chemical calculations. ${ }^{7}$ Therefore in this paper we focus on the theoretical modeling reaction by semiempirical method.

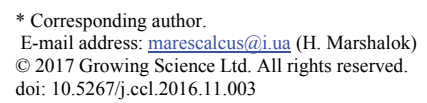


The quantum-chemical modeling mechanism of the [4+2]-cycloaddition reaction of 2,3-dimethylbuta-1,3-diene and methyl acrylate was conducted and allows us to analyze its qualitative aspects at the molecular level. Also the theoretical analysis of the synthesized product methyl3,4-dimethylcyclohex-3-encarboxylate structure was presented. Furthermore, in order to confirm the proposed mechanism we have found agreement between the experimental reaction activation parameters and obtained by quantum-chemical calculations.

The reaction of 2,3-dimethylbuta-1,3-diene with alkyl methacrylates belongs to the pericyclic reactions ${ }^{3}$ and can proceeds according to the concerted mechanism in a one-step or two-step interaction between atoms. The one-step pathway can occur through synchronous or asynchronous transition states. Two-step interaction taking place via biradical or zwitterionic transition states.

For example, in the work ${ }^{9}$ a variety of symmetrical or nearly symmetrical Diels-Alder reactions of bis(boryl)acetylenes, dialkyl acetylenedicarboxylates, triazolinediones, and dialkyl maleates were studied. The results of theoretical calculations by Becke3LYP were confirmed by rate observations and kinetic isotope effects. Firestone in his work ${ }^{10}$ was investigated the role of heavy atom effects in DielsAlder reactions in support of a stepwise-biradical mechanism. The dimerization of chloroprene analyzed via a dual mechanism was seen as unified. The illustration of two-step zwitterionic mechanism was showed by B3LYP/6-31++G(d) calculations in the reaction of (2E)-3-phenyl-2-nitroprop-2enenitrile with cyclopentadiene catalyzed by cations of 1,3-dialkylimidazolium ionic liquid. ${ }^{11}$ There are many studies $2,3,5,12$ where authors by different methods of calculations obtain information about the mechanism of these kind reactions. In the article, ${ }^{5}$ authors suggest that Diels-Alder reactions in general proceed via very unsymmetrical transition states, close to biradicals in structure and with energies differing little from those of the corresponding biradicals. Investigating the interaction of cyclopentyne with ethene authors used (U)B3LYP and CASSCF methods. ${ }^{2}$ (U)B3LYP/6-31G* and (U)B3LYP/6-311+G* slightly favor the concerted pathway, whereas CASSCF $(4,4) / 6-31 \mathrm{G}^{*}$ and $\operatorname{CASCF}(6,6) / 6-31 \mathrm{G}^{*}$ favor the biradical pathway.

\section{Computational Methods}

The quantum-chemical study of the mechanism of 2,3-dimethylbuta-1,3-diene (DMB) and methyl acrylate (MA) interaction was carried out using MOPAC $2012^{13}$ and a graphic user interface Winmostar. ${ }^{14}$ To optimize the geometry and calculate the reaction states heat of formation $\left(\Delta_{f} H^{298}\right)$, the electron energy $\left(\mathrm{E}_{\mathrm{el}}\right)$ and internuclear interaction $\left(\mathrm{E}_{\mathrm{C}-\mathrm{C}}\right)$, dipole moment $(\mu)$, the ionization potential $(\mathrm{I})$ and the definition of the reaction path were used semiempirical method RM1 with normalization factor for energy from 0.01 to $0.5 \mathrm{kcal} / \mathrm{mol} \cdot \AA$. This calculation method is used due to the fact that it allows optimizing the geometry of the molecules, which consists atoms of the elements $\mathrm{C}, \mathrm{H}$ and $\mathrm{O}$, with the smallest error for the bond lengths and angles between them in comparison with other methods neglect of diatomic differential overlap (MNDDO). ${ }^{15}$ Application of quantum-chemical calculations COSMO model (parameter EPS $=\mathrm{xx}$ ), which takes into account the permittivity $(\varepsilon)$ of the condensed phase, allows the comparison of the experimental and theoretical thermodynamic reaction parameters. ${ }^{16,17} \mathrm{In}$ our case, the parameter used in calculating EPS $=2.1$, which simulates a reaction medium DMB with $\varepsilon=2.1^{18}$

Thermodynamic parameters (enthalpy $\mathrm{H}$, the heat capacity $\mathrm{C}_{\mathrm{p}}$, the entropy $\mathrm{S}$ ) for different reaction conditions expected in the temperature range 403-433 K using the function THERMO $(403,433,10)$, which allowed to determine the enthalpy $\left(\Delta \mathrm{H}^{\#}\right)$ and entropy $\left(\Delta \mathrm{S}^{\#}\right)$ activation. Calculation of DMB and MA [4+2]-cycloaddition was carried out by using restricted (RHF) and unrestricted (UHF) HartreeFock approximation according to the internal coordinate Z-matrix of the initial reaction state of DMB with MA [4+2]-cycloaddition. In the internal coordinates Z-matrix of the initial reaction state the reference atoms indicates by the number of atom in the molecule, and for each coordinate adds additional identifiers, showing the need to vary this parameter during the optimization, or to keep its value constant. The interatomic distances for all reaction structures are presented in Table 1. 
Construction of the potential energy surface (PES) DMB and MA [4+2]-cycloaddition was carried by two reaction coordinates $\mathrm{d}(\mathrm{C} 4-\mathrm{C} 8)$ and $\mathrm{d}(\mathrm{C} 1-\mathrm{C} 7)$ from 3.1 to $1.5 \AA$ with step $-0.02 \AA$ and calculated the potential energy in a particular state of the reaction system. The potential energy surfaces of DMB and MA [4+2]-cycloaddition possible reaction pathways were constructed on the results of calculations using the RHF (Fig. 1) and UHF (Fig. 2).

Table 1. Geometric parameters of the reaction structures of DMB and MA [4+2]-cycloaddition

\begin{tabular}{lcccccc}
\hline \multirow{2}{*}{ Reaction structures } & \multicolumn{7}{c}{ Bond length, $\AA$} \\
\cline { 2 - 6 } & $\mathrm{C}(2)-\mathrm{C}(1)$ & $\mathrm{C}(3)-\mathrm{C}(2)$ & $\mathrm{C}(4)-\mathrm{C}(3)$ & $\mathrm{C}(8)-\mathrm{C}(7)$ & $\mathrm{C}(8)-\mathrm{C}(4)$ & $\mathrm{C}(7)-\mathrm{C}(1)$ \\
\hline DMB + MA & 1.332 & 1.464 & 1.332 & 1.330 & 3.100 & 3.100 \\
T11 & 1.361 & 1.427 & 1.410 & 1.393 & 1.977 & 3.010 \\
I1 & 1.377 & 1.403 & 1.486 & 1.469 & 1.530 & 3.681 \\
T12 & 1.390 & 1.393 & 1.483 & 1.476 & 1.539 & 2.457 \\
T21 & 1.413 & 1.425 & 1.363 & 1.397 & 2.936 & 1.979 \\
I2 & 1.484 & 1.402 & 1.377 & 1.472 & 3.099 & 1.542 \\
T22 & 1.483 & 1.392 & 1.391 & 1.477 & 2.433 & 1.545 \\
TS & 1.376 & 1.409 & 1.382 & 1.386 & 2.077 & 2.173 \\
P $_{\text {eq }}$ & 1.490 & 1.337 & 1.490 & 1.526 & 1.524 & 1.528 \\
\hline
\end{tabular}

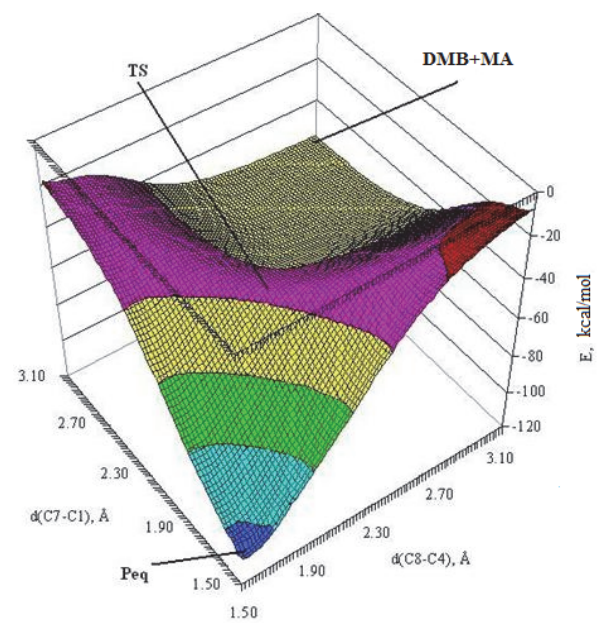

Fig. 1. Potential energy surface of DMB and MA [4+2]-cycloaddition reaction calculated by RHF

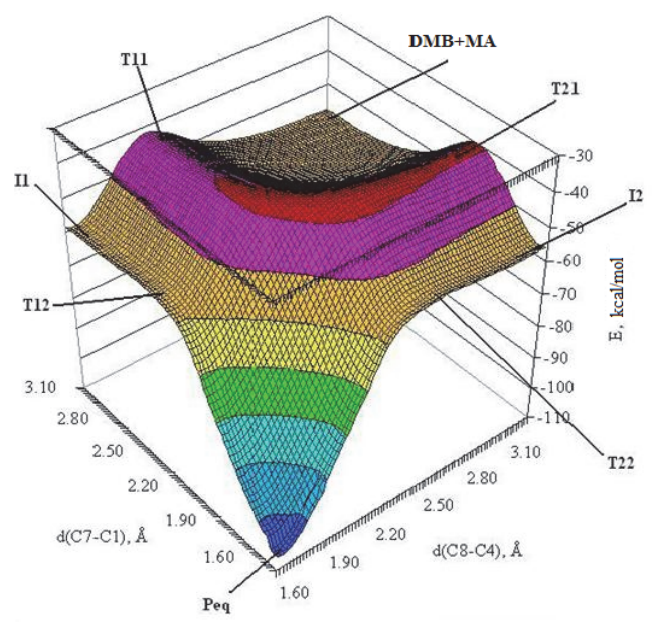

Fig. 2. Potential energy surface of DMB and MA [4+2]-cycloaddition reaction calculated by UHF

\section{Results and Discussion}

On the scheme presents the possible reaction pathways of DMB and MA [4+2]-cycloaddition calculated using the RHF and UHF approximations. According to the one-step mechanism RHF interaction occurs through the formation of transition state TS and a two-step UHF interaction occurs through the formation of transition state T11, intermediate I1 and transition state T12 or through the formation of transition state T21, intermediate I2 and transition state T22 with priority interaction between different atoms multicenter interactions.

Table 2. Energy parameters of the reaction conditions of DMB and MA [4+2]-cycloaddition

\begin{tabular}{lccccc}
\hline \multirow{2}{*}{ Reaction structures } & \multicolumn{5}{c}{ Energy parameters } \\
\cline { 2 - 6 } DMB + MA & $\Delta_{f} H^{298}, \mathrm{kcal} / \mathrm{mol}$ & $\mathrm{E}_{\mathrm{el}, \mathrm{eV}}$ & $\mathrm{E}_{\mathrm{C}-\mathrm{C}, \mathrm{eV}}$ & $\mu, \mathrm{D}$ & $\mathrm{I}, \mathrm{eV}$ \\
\hline T11 & $\mathbf{- 5 7 . 9}$ & -11321.1 & 9209.0 & 2.08 & 9.29 \\
I1 & $\mathbf{- 4 1 . 7}$ & -11685.6 & 9574.3 & 2.15 & 8.54 \\
T12 & -60.5 & -11449.1 & 9336.9 & 1.51 & 8.53 \\
T21 & -57.5 & -11840.7 & 9728.6 & 1.93 & 8.54 \\
I2 & $\mathbf{- 3 9 . 7}$ & -11671.2 & 9559.9 & 2.08 & 8.56 \\
T22 & -56.2 & -11675.2 & 9563.2 & 1.96 & 8.55 \\
TS & -54.4 & -11763.3 & 9651.4 & 1.83 & 8.53 \\
Peq $_{\text {eq }}$ & $\mathbf{- 3 7 . 3}$ & 11860.5 & 9749.3 & 2.23 & 8.81 \\
\hline
\end{tabular}




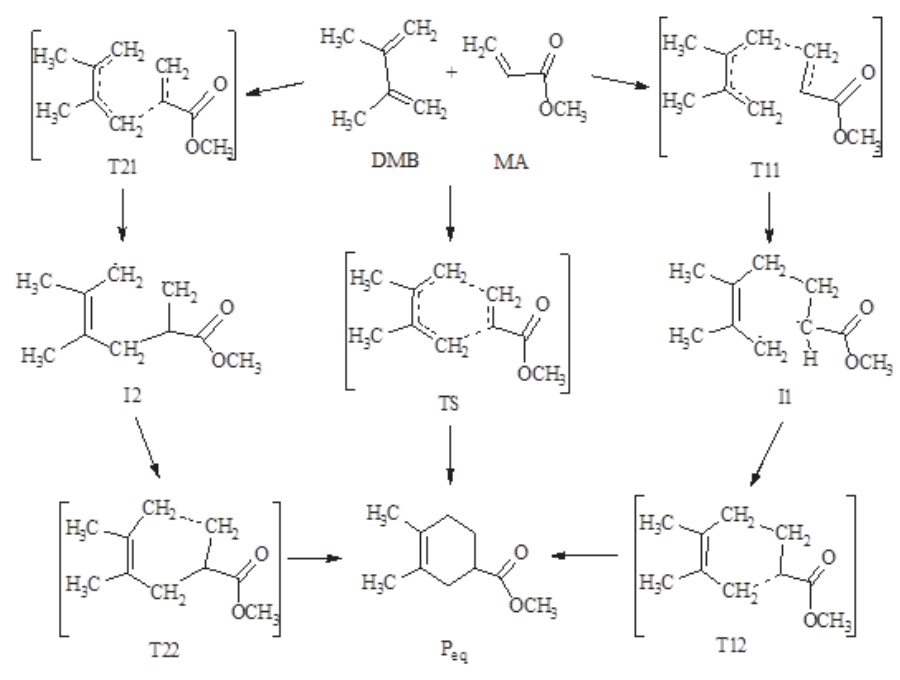

Scheme.1 Mechanisms of DMB and MA [4+2]-cycloaddition

Reaction occurs between the frontier molecular orbitals (FMO) an electron donor DMB and an electron acceptor MA at the supra placing reactants. In our case, as seen in Fig. 3, multicenter interaction occurs between atoms $C(1)$ and $C(4)$ diene system of DMB with the atoms $C(7)$ and $C(8)$ $\pi$-system of MA. ${ }^{17}$ The numbering atoms (Fig. 3) corresponds the numbers of atoms in the internal coordinate Z-matrix. In the case of one-step interaction DMB and MA reaction overcomes through transition state TS energy barrier (Scheme, Fig.1). The activation energy of this interaction Ea (TS) calculated by RHF and composes $20.6 \mathrm{kcal} / \mathrm{mol}$ (Table 2):

$$
\mathrm{E}_{\mathrm{a}}(\mathbf{T S})=\Delta_{f} H^{298}(\mathbf{T S})-\Delta_{f} H^{298}(\mathbf{D M B}+\mathrm{MA})=\mathbf{- 3 7 . 3}+\mathbf{5 7 . 9}=\mathbf{2 0 . 6}(\mathrm{kcal} / \mathrm{mol})
$$

Regarding the possibility of the passage of the two-step reaction mechanism, the analysis of the potential energy surface, obtained by using UHF calculations (Fig. 2) indicates that the interaction of $\mathrm{DMB}$ as diene and MA as dienophile may extend two ways: with the priority of the interaction $\mathrm{C}(4)$ and $\mathrm{C}(8)$ atoms (T11-I1-T12 way) or priority between $\mathrm{C}(1)$ and $\mathrm{C}(7)$ atoms (T21-I2-T22 way) (scheme).

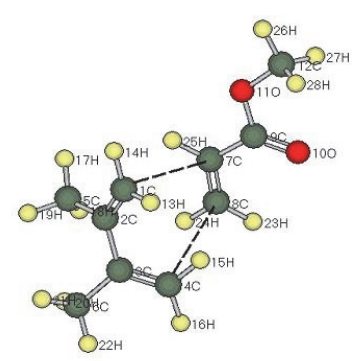

DMB+MA

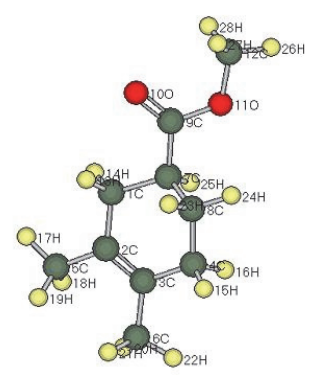

$P_{e q}$

Fig. 3. Optimized model of the initial state $(\mathrm{DMB}+\mathrm{MA})$ and the final product $\left(\mathrm{P}_{\mathrm{eq}}\right)$ of $\mathrm{DMB}$ and $\mathrm{MA}$ [4+2]-cycloaddition

According to the first path T11-I1-T12 reaction can take place via transition state T11 and the energy barrier Ea (T11) is equal to $16.2 \mathrm{kcal} / \mathrm{mol}$ (Table 2):

$$
\mathrm{E}_{\mathrm{a}}(\mathbf{T 1 1})=\Delta_{f} H^{298}(\mathbf{T 1 1})-\Delta_{f} H^{298}(\mathbf{D M B}+\mathrm{MA})=\mathbf{- 4 1 . 7}+\mathbf{5 7 . 9}=\mathbf{1 6 . 2}(\mathrm{kcal} / \mathrm{mol})
$$


Formation of the metastable intermediate I1 and transition state $\mathrm{T} 12$, followed by reacting $\mathrm{C}(7) \mathrm{MA}$ and C(1) DMB atoms takes place stepwisely and also leads to the desired product $\mathrm{P}_{\mathrm{eq}}-$ methyl3,4-dimethylcyclohex-3-encarboxylate, wherein the carboxylate group is in the exo-orientation to the cyclohexene ring (Fig. 3). Cycle formation occurs at the outlet transition state T12 with disrotatory rotation frontier orbitals of $\mathrm{C}(1)$ and $\mathrm{C}(7)$ reaction state atoms.

According to the second way of T21-I2-T22 reaction can also take place on a two-step mechanism (Table 3) via transition state T21 overcoming the energy barrier Ea (T21) (Table 2) and the subsequent formation of the intermediate $\mathrm{I} 2$, transition state $\mathrm{T} 22$ to the product $\mathrm{P}_{\mathrm{eq}}$ :

$$
\mathrm{E}_{\mathrm{a}}(\mathbf{T} 21)=\Delta_{f} H^{298}(\mathbf{T} 21)-\Delta_{f} H^{298}(\mathbf{D M B}+\mathrm{MA})=\mathbf{- 3 9 . 7}+\mathbf{5 7 . 9}=\mathbf{1 8 . 2}(\mathrm{kcal} / \mathrm{mol})
$$

Table 3. Experimental and calculated in the RHF and UHF approximations activation parameters of 2,3-dimethyl-1,3-diene and methyl acrylate [4+2]-cycloaddition

\begin{tabular}{lccc}
\multicolumn{1}{c}{ Options } & $\begin{array}{c}\mathrm{E}_{\mathrm{a}}, \\
\mathrm{kcal} / \mathrm{mol}\end{array}$ & $\begin{array}{c}\Delta \mathrm{H}^{\#}, \\
\mathrm{kcal} / \mathrm{mol}\end{array}$ & $\begin{array}{c}\Delta \mathrm{S}^{\#}, \\
\mathrm{kcal} / \mathrm{mol} \cdot \mathrm{K}\end{array}$ \\
\hline Experimental & $\mathbf{1 6 . 9}$ & 16.5 & -34.2 \\
Calculated ( T11-I1-T12) (UHF) & $\mathbf{1 6 . 2}$ & 15.9 & -32.8 \\
Calculated (T21-I2-T22) (UHF) & 18.2 & 17.4 & -40.7 \\
Calculated (TS) (RHF) & 20.6 & 20.1 & -41.9 \\
\hline
\end{tabular}

As the second way requires a large amount of energy to overcome the energy barrier in comparison with the first, it is likely the reaction will take place on the first path, and the energy gain in this case is:

$$
\mathrm{E}_{\mathrm{a}}(\mathbf{T} 21)-\mathrm{E}_{\mathrm{a}}(\mathbf{T} 11)=\mathbf{1 8 . 2}-\mathbf{1 6 . 2}=\mathbf{2}(\mathrm{kcal} / \mathrm{mol})
$$

If we compare the calculation results of the activation parameters obtained using unrestricted and restricted Hartree-Fock, should be given the benefit data that indicate the passage of a two-step process according to the stepwise biradical mechanism UHF, and not by one-step concert mechanism RHF. Since the passage of the two-step process according to the concerted mechanism requires less energy to overcome the energy barrier.

$$
\mathrm{E}_{\mathrm{a}}(\mathbf{T S})-\mathrm{E}_{\mathrm{a}}(\mathbf{T 1 1})=\mathbf{2 0 . 6} \boldsymbol{- 1 6 . 2}=\mathbf{4 . 4}(\mathrm{kcal} / \mathrm{mol})
$$

On the potential energy surfaces (Fig. 1, 2) calculated maxima TS, T11, T12, T21 and T22 are saddle points of the surface, and the points I1 and I2 - intermediate local minima, whose existence is confirmed by vibration analysis and calculation of the internal reaction coordinate (IRC). The final product $\mathrm{P}_{\text {eq }}$ molecule (Fig. 3) has form of a half-chair. Namely, a cyclohexene ring moieties are diene and dienophile in an antara position. Specifically, C(1) and C(4) atoms are from different sides of the plane of formed cycle. This indicates that the interaction between DMB and MA molecules, whose planes are at the beginning of the reaction supra-superficially occurs step by step with disrotator ring closure in a second step. Furthermore, based with our experimental and quantum-chemically calculated activation parameters of DMB and MA [4+2]-cycloaddition (Table 3), it can be claimed that the proposed two-step reaction mechanism UHF is more likely than one-step RHF, since the energy and enthalpy of activation of this interaction UHF maximum coincide with the experimental data, in contrast to RHF.

\section{Conclusions}

The mechanism of 2,3-dimethylbuta-1,3-diene with methyl acrylate [4+2]-cycloaddition was investigated by quantum chemical modeling. The calculation results of the activation parameters and analysis the obtained potential energy surfaces using unrestricted and restricted Hartree-Fock indicate the passage of the process according to the stepwise biradical mechanism UHF, rather than one-step 
concerted mechanism with RHF. The energy barrier of the reaction pass according to the stepwise biradical mechanism is smaller compared to the one-step interaction.

The final product methyl-3,4-dimethylcyclohex-3-encarboxylate molecule has half-chair form. The structure of this molecule also indicates that the reaction between 2,3-dimethylbuta-1,3-diene as diene and methyl acrylate as dienophile passes through a stepwise mechanism with disrotator ring closure in a second step.

\section{References}

1 Firestone R. A. (2013) The Low Energy of Concert in Many Symmetry-Allowed Cycloadditions Supports a Stepwise-Diradical Mechanism. Int. J. Chem. Kinet., 45 415-428.

2 Bachrach S. M. and Gilbert J. C. (2004) The Reaction of Cyclopentyne with Ethene: Concerted vs Stepwise Mechanism? J. Org. Chem., 69 (19) 6357-6364.

3 Morgan K. M. (2005) 11 Reaction mechanisms. Part (iii) Pericyclic reactions. Annu. Rep. Prog. Chem., Sect. B: Org. Chem., 101 284-304.

4 Carruthers W. (1990) Cycloaddition Reactions in Organic Synthesis. Von Pergamon Press, Oxford.

5 Dewar M. J. S., Olivella S., Stewart J. J. P. (1986) Mechanism of the Diels-Alder reaction: reactions of butadiene with ethylene and cyanoethylenes. J. Am. Chem. Soc., 108 (19) 5771-5779.

6 Dykstra C., Frenking G., Kim K., Scuseria G. (2005) Theory and Applications of Computational Chemistry: The First Forty Years. $1^{\text {st }}$ edition, Elsevier, Amsterdam.

7 Jensen F. (2007) Introduction to Computational Chemistry. $2^{\text {nd }}$ edition, John Wiley \& Sons Ltd, England.

8 Brückner R. (2010) Hardcover Organic Mechanisms - Reactions, Stereochemistry and Synthesis. Springer Berlin Heidelberg.

9 Singleton D.A., Schulmeier B.E., Hang C., Thomas A.A., Leung S.-W., Merrigan S.R. (2001) Isotope effects and the distinction between synchronous, asynchronous, and stepwise Diels-Alder reactions. Tetrahedron, 57 (24) 5149-5160.

10 Firestone R. A. (1996) Volume of concert and heavy atom effects in Diels-Alder reaction mechanisms. Tetrahedron, 52 (46) 14459-14468.

11 Jasiński R. (2016) First example of stepwise, zwitterionic mechanism for bicyclo[2.2.1]hept-5-ene (norbornene) formation process catalyzed by the 1-butyl-3-methylimidazolium cations. Monatsh Chem. 147 (7) 1207-1213.

12 Morales-Bayuelo A., Vivas-Reyes R. (2013) Topological model to quantify the global reactivity indexes as local in Diels-Alder reactions, using density function theory (DFT) and local quantum similarity (LQS). J. Math. Chem., 51 (1) 125-143.

13 Stewart J.J.P. Program Package MOPAC2012 (http://www.openmopac.net).

14 Senda N. Program Package Winmostar (http://winmostar.com).

15 Stewart J.J.P. (2007) Optimization of parameters for semiempirical methods V: Modification of NDDO approximations and application to 70 elements. J. Mol. Model., 13 (12) 1173-1213.

16 Konovalov A. I., Kiselev V.D. (2003) Diels-Alder reaction. Effect of internal and external factors on the reactivity of diene-dienophile systems. Russian Chemical Bulletin., 52 (2) 293-311.

17 Kovalskyi Ya. P., Kostiv I. S., Marshalok O I., Marshalok H. O., Pyrig I. Yu. (2014) Quantumchemical research of the reaction mechanism of [4+2]-cycloaddition of 2,3-dimethylbuta-1,3-dien and allylmethacrylate. Eastern-European Journal of Enterprise Technologies. 5-6 (71) 32-36.

18 Spravochnik Chimika. (1966). Part 1 Moscow: «Chimiya».

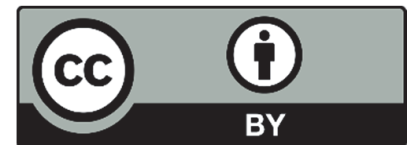

(C) 2016 by the authors; licensee Growing Science, Canada. This is an open access article distributed under the terms and conditions of the Creative Commons Attribution (CC-BY) license (http://creativecommons.org/licenses/by/4.0/). 